\title{
Research on Innovation Teaching Model of National Instrumental Music in Colleges and Universities
}

\author{
Guo-yangyang \\ Nanyang Institute of Technology,Nanyang,China \\ 10707247@qq.com
}

Keywords: Universities, National Instrumental Music, Teaching Models, Innovation

\begin{abstract}
Traditional music is an important part of China's national instrumental music. It has a large number of traditional music. However, the traditional music is not as rich in performance techniques as the modern composition music, and its spin characteristics are different from the western music theory system used in various stages of school education in China, which results in traditional music not being used in the national instrumental music teaching in colleges and universities. The importance attached. Traditional music plays a positive role in opening up students' diverse musical perspectives, improving students' humanistic qualities, and promoting the traditional culture of the Chinese nation. Therefore, we should promote the teaching of traditional music in the teaching of national instrumental music in colleges and universities by strengthening the construction of teaching materials, enriching teaching methods and emphasizing practical exercises.
\end{abstract}

\section{Introduction}

China's national musical instruments are not only diverse, but each instrument has a long history. In the long process of development, each instrument has accumulated a large number of performances, which has added beautiful colors to the treasure trove of Chinese folk music[1]. These numerous ethnic instruments can be divided into two categories: "traditional music" and "modern contemporary composition." The traditional music refers to the music created before the 1950s. The modern music refers to the music that has influenced the composition of Western composing techniques since the 1950s. Traditional music and modern composition music have their own characteristics, representing the inheritance and innovation of Chinese instrumental music. In the teaching of national instrumental music in colleges and universities, the teaching of the two types of music has its own characteristics and meanings[2]. It is indispensable for students.

\section{The Present Situation of Traditional Music Teaching in College National Instrumental Music Teaching}

In traditional Chinese instrumental music, there are many works with hundreds of years of history, such as "The Dharma on the Deck" and the Guqin Song. It also has the "Zhuge Plays" and the Erhu "Er Quan Yingyue", such as music with distinctive regional characteristics. These traditional music pieces not only have distinct historical features, but also reflect the long history and cultural connotation of Chinese traditional instrumental music culture, and they also have strong regional characteristics. They are inextricably linked with folk music cultures in different regions of China. As an important part of traditional music culture, traditional folk instrument music should be given full attention by all instrument players and learners[3]. However, in view of the current major universities in our country, whether it is a professional college, an ordinary college or a normal university, in the process of professional teaching, teachers have not placed the traditional music teaching on an important position. Modern and contemporary composition music is the main components of the current national instrumental music teaching in colleges and universities.

\section{The Reason Why Traditional Music Is Not Valued in Teaching}

The teaching of traditional music is not valued in the current national instrumental music teaching 
in colleges and universities. The reasons are closely related to the background of the times, cultural environment and other factors[4]. Among them, the relative lack of rich playing techniques and the characteristics of the spin characteristics based on the characteristics of traditional music are the main reasons for the cold.

The Disadvantages of Playing Techniques. After the founding of the People's Republic of China, influenced by the techniques of composing in the West, China's music creation has changed greatly in terms of creative ideas and creative techniques. In this context, modern and contemporary national instrumental music created in the context of the type of creation, the subject matter genre, the connotation conception, etc., have manifested characteristics different from the traditional ones. In order to satisfy the needs of these modern and contemporary musical instruments, a large number of new playing techniques were born and widely promoted, making the performance techniques used in modern and contemporary composition music reflect the features of blending ancient and modern. In contrast, the performance of traditional music is not rich enough. In addition, most of the new techniques are difficult to perform, so the modern and contemporary composition music played by them can satisfy the needs of the performers in professional competitions, professional concerts, and other occasions. The disadvantage of traditional music in playing techniques is one of the reasons why it cannot be given enough attention in college instrumental music teaching.

Differences in Rotation Characteristics. Due to the complete westernization of the music education model, the main body of our national culture and art has been lost in school music education. At present, in our country's music education system, the basic theory of Western music occupies an absolute core position[5]. Whether it is the music curriculum in primary and secondary schools or the university's professional music teaching, the Western music system is adopted. Even if students play in the direction of national instrumental music, the knowledge of music theory, harmony, etc. they learn is also part of the Western music system. In the imperceptible, the Chinese people's musical aesthetics tend to the Western tone system, harmony layout, and musical structure, but it is unfamiliar to the traditional Chinese music structure. Therefore, the traditional folk music that is rooted in the traditional music culture of China has the national style, national swirling method, and national connotation that cannot arouse enough resonance among present performers and appreciators, resulting in traditional music being relatively weak in the teaching of ethnic instrumental music.

\section{The Significance of Strengthening Traditional Music Teaching in Colleges and Universities}

The instrumental music of the Chinese national instrumental music, after thousands of years of scouring, and the musical instruments or musical instruments that have been circulated so far, all contain profound Chinese culture, humanistic spirit, and high aesthetic value. It is an important part of Chinese folk music[6]. Despite the disadvantages of playing techniques and the differences in the characteristics of spinning techniques, the traditional music pieces have not received due attention in the current national instrumental music teaching in colleges and universities. However, the cultural connotation and traditional essence contained in traditional music pieces are used to open up students' diverse musical perspectives and improve students' abilities. The humanistic qualities of the people and the promotion of the traditional culture of the Chinese nation have a positive effect, as shown in Figure 1.

Develop Multivariate Perspectives. The 21st century is a new era of diversity. As a student of national instrumental music, it is also necessary to use a diversified perspective to examine its own profession. Modern and contemporary composition tracks reflect the innovation of Chinese national instrumental music based on the combination of Chinese and Western cultures after the founding of the PRC. The musical composition of these songs, the application of harmony, and the means of music development have absorbed the essence of Western music and represented a new form of national instrumental music. sound. The traditional music contains thousands of years of Chinese cultural heritage. Its rich cultural connotation and simple and elegant music style represent the ancient rhyme of the national instrumental music. For learners of ethnic instrumental music, it is only when they inherit the ancient rhyme and make new innovations at the same time that they can 
truly achieve diversified development.

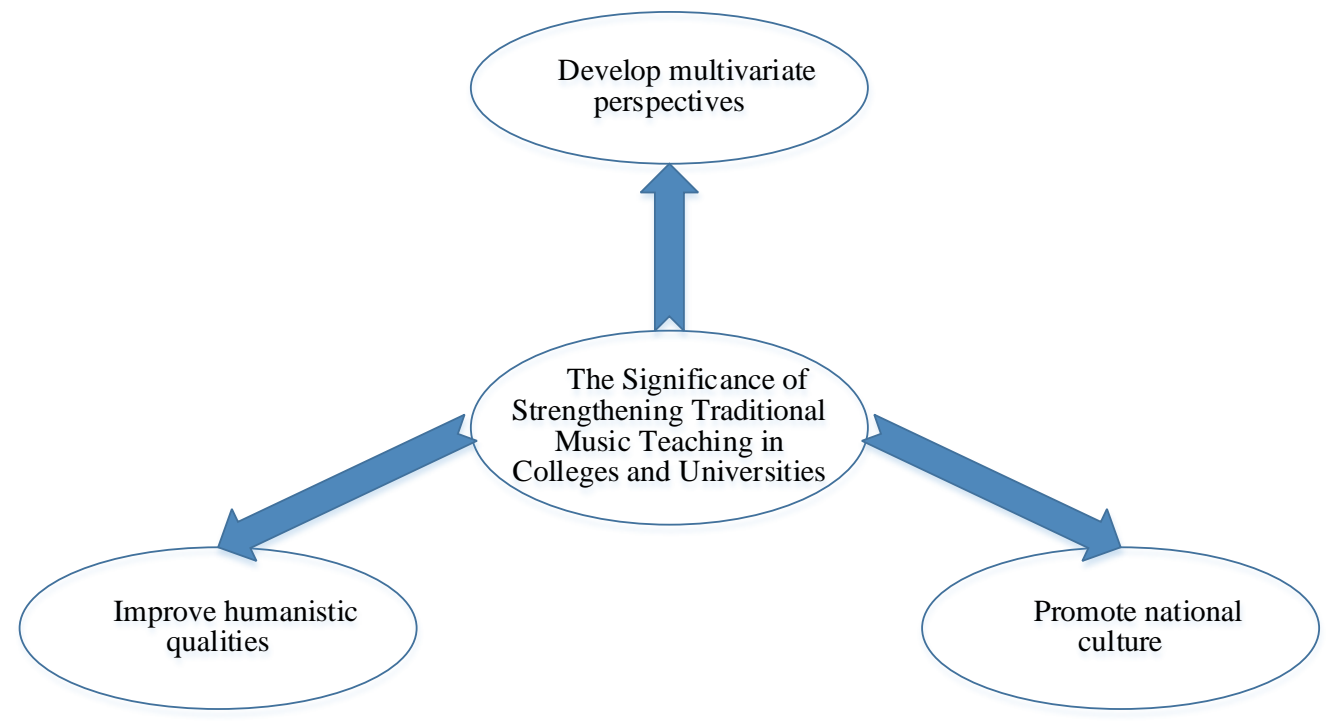

Figure 1. The significance of strengthening traditional music teaching in colleges and universities

Improve Humanistic Qualities. Among the national musical instruments in our country, there are many musical instruments with cultural attributes such as guqin and pipa. These musical instruments were loved by literary men of all ages. At the same time, the traditional music created by these literati are also endowed with profound cultural connotations. Playing these traditional music not only requires the performer to master the skills of the music, but also requires the performer to create a second creation of the music based on his own emotional experience on the basis of a deep understanding of the cultural connotation of the work. The characteristics of music, such as "harmony" and "beauty" included in traditional music, are of great help to improving students' literary quality.

Promote National Culture. Lu Xun once said: "Only ethnic people are the world." The unique national culture of each nation is an integral part of the colorful world culture. Only rooted in the fertile soil of national culture can we shine in the forest of world culture. Promoting national culture is a responsibility that every Chinese should do. It is even more a responsibility for college students in the new era. Traditional music is an important part of the national music culture. Conscientiously studying traditional music and making listeners like traditional music and understanding traditional music through their own performances is one of the ways that national instrumental music students promote national culture.

\section{The Main Measures to Improve the Traditional Music Teaching in Colleges and Universities}

As mentioned above, traditional music plays a positive role in exploring multiple perspectives, improving humanistic qualities, and promoting national culture. Therefore, in the instrumental teaching of colleges and universities in the country, traditional music should be given enough attention. To enhance the teaching of traditional music, we can start from several aspects: strengthen the construction of teaching materials, enrich teaching methods, and focus on practice, as shown in Figure 2.

Strengthen the Construction of Teaching Materials. Since Liu Tianhua introduced national instrumental music into the ranks of higher education, China's national instrumental music teaching has also drawn new and continuous development on the basis of Western musical instrument teaching. The degree of professionalism in the national instrumental music teaching has been continuously strengthened. However, problems such as the single type of teaching materials and the lack of standardization are also a major factor restricting the development of national instrumental music teaching in colleges and universities. At present, the national instrumental music teaching in China's colleges and universities lacks a comprehensive and uniform teaching material. The use of 
teaching materials by teachers is generally based on examination materials. Looking at the test scores of various musical instruments, it is not difficult to find that the modern music that emphasizes the use of playing techniques is the main component of the test scores, and the proportion of traditional music is low. Teaching materials are the foundation of student learning. A good teaching material can provide students with good help. Therefore, to improve the teaching of traditional instrumental music in colleges and universities, we should begin with the construction of textbooks, and write a professional textbook that is suitable for difficulty, with both etudes and music, traditional music, and contemporary music. In the traditional music section, in addition to the detailed music introductions, various versions of the music's different schools should also be included. This will not only enable students to have a comprehensive and in-depth understanding of the origin, circulation, content, and concept of the music, but also allow students to in the process of second creation, it is possible to integrate the lengths of each school and complete the interpretation of the works more accurately, comprehensively and vividly.

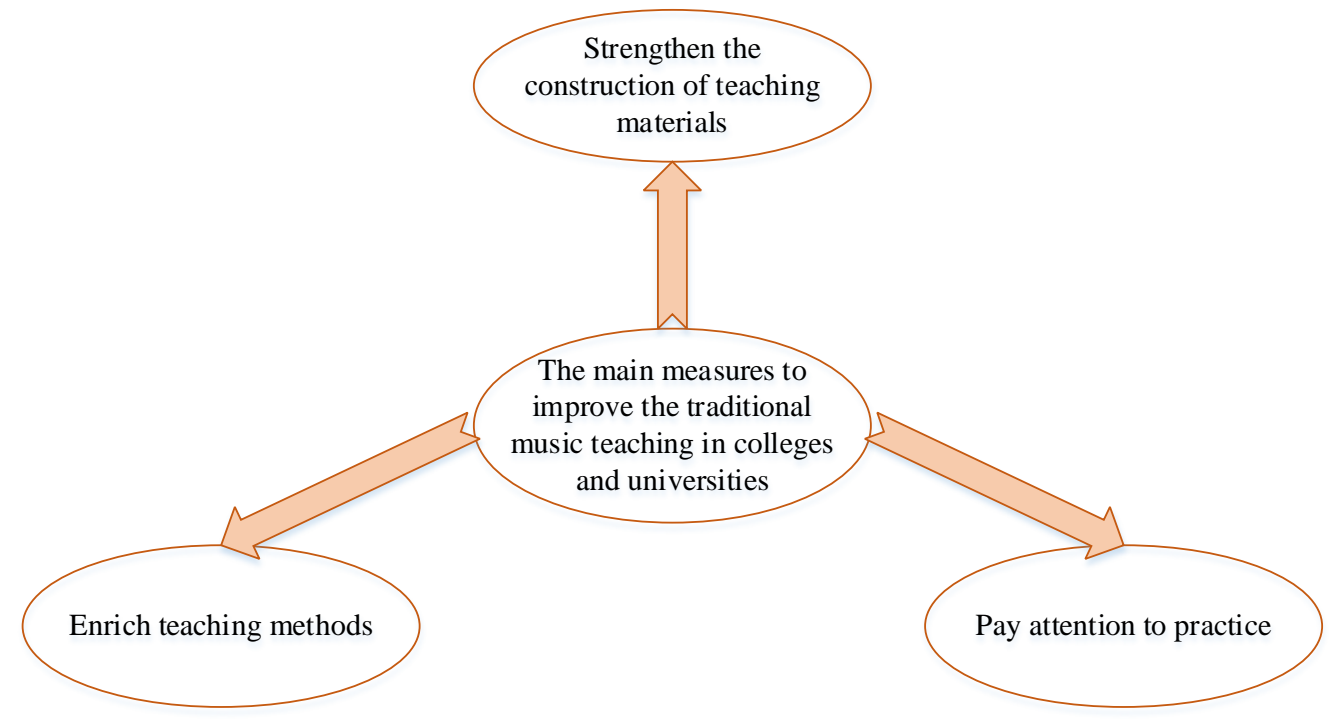

Figure 2. The main measures to improve the traditional music teaching in colleges and universities

Enrich Teaching Methods. In recent years, various types of colleges and universities in China have adjusted and innovated the teaching of national instrumental music. The continuous popularization of group lessons and the continuous improvement of related courses such as the folk music ensemble class are all signs of the increasingly mature national instrumental music teaching in Chinese universities and colleges. For the traditional music teaching, it can also be improved from the following aspects. First, strengthen the teaching of relevant theoretical knowledge. Traditional music is rooted in traditional culture and folk music. Teachers should combine music and teach national music, traditional music structure and other relevant knowledge in teaching process, so that students can have a complete and correct understanding of the music composition and structure. Second, the teaching of folk music rendition should be reasonably increased. In our country's national instrumental music, ensemble is an important part. Its importance is no less than solo. It has a large number of songs and a rich regional style. The techniques of adding flowers, variations, etc. that are often used in the replays are also very helpful in improving students' ability to create their second creation. Third, arrange appropriate folk collecting activities. Folk artists have long been influenced by local customs, humanistic traditions, and are one of the main strengths of the prosperity and development of folk art. The music inherited, created and performed by folk artists often has rich ethnic flavor and heavy traditional heritage. Through folk activities, close contact with folk artists and appreciation of the original folk music can, to a certain extent, enhance the students' understanding of the national music culture and thus more systematically grasp the style of traditional music.

Pay Attention to Practice. For music majors, practice is an essential part of professional learning. Practice can not only report the students' learning situation, but also exercise the students' 
stage performance. For the practice of traditional music teaching, in addition to attending concerts, comprehensive evening parties, and professional competitions, teachers can also build practical platforms for students through the following methods. First, regular concerts of traditional music are organized regularly. Compared to other types of concerts and evening parties, the special concerts of traditional music not only provide students with more opportunities to play traditional music, but this kind of special concert is also very helpful for the promotion of traditional music. Second, recommend students to join the folk orchestra. The rehearsal rehearsal, rehearsal style, and music audience of the folk orchestra are different from those of the school folk orchestra and professional groups. The practical experience of the folk orchestra can help students deepen their understanding of traditional music. This same method can also help the folk orchestra to supplement the fresh blood. Promote the sustainable development of these orchestras. Finally, participation in traditional arts festivals, programming related programs and other methods can also improve students' ability to play traditional music.

\section{Conclusion}

Traditional Chinese music often gives people a sense of elegance and a broad sense of the sea. It has been widely circulated in China's land for thousands of years and has been loved by music lovers both at home and abroad. However, after the founding of the People's Republic of China, all aspects of traditional Chinese culture were affected by Western culture. The living space of many traditional arts was squeezed and traditional music was no exception. Learning and mastering the performance of traditional music is beneficial for students to fully grasp a musical instrument, which is beneficial to the improvement of students' humanistic qualities and is conducive to the spread of traditional music. Therefore, it should arouse the attention of teachers and students in colleges and universities. The several measures proposed in the article to improve the traditional music teaching in colleges and universities are the more feasible methods accumulated and summarized by the author in the teaching process. Their objectivity and comprehensiveness are to be continuously tested and perfected in the teaching practice.

\section{References}

[1] Parkinson T. Mastery, Enjoyment, Tradition and Innovation: A Reflective Practice Model for Instrumental and Vocal Teachers.[J]. International Journal of Music Education, 2016, 34(3): 352-368.

[2] Polk K. Patronage and Innovation in Instrumental Music in the 15th Century[J]. Historic Brass Society Journal, 1991, 3:151-178.

[3] Schoening K. Tradition and Innovation in the Application Mode in the Instrumental Music of 16(th) Century[J]. Musikforschung, 2014, 67(2):134-153.

[4] Zhou Bangchun, Shi Jin. Research on the Reform and Innovation of National Instrumental Music Teaching in Local Colleges and Universities in the Background of Transition[J]. Musical Works, 2016, 10: 192-194.

[5] Pang Rong. A brief discussion on the integration of inheritance and time in the teaching of national instrumental music in colleges and universities[J]. Song of the Yellow River, 2017, 17: 56.

[6] Lu Yingying. Comparative study on teaching of national instrumental music in fujian and Taiwan universities[J]. Art Evaluation, 2017, 23: 107-109. 